\title{
Comparative evaluation of concrete sand-control fences used for railway protection in strong wind areas
}

\author{
Long $\mathrm{Shi}^{1} \cdot$ Dongyuan $\mathrm{Wang}^{2} \cdot \mathrm{Kai}^{\mathrm{Cui}}{ }^{2} \cdot$ Chunxiao Xue $^{3}$
}

Received: 13 August 2020/Revised: 16 December 2020/Accepted: 18 December 2020/Published online: 16 January 2021

(C) The Author(s) 2021

\begin{abstract}
Concrete-plate fences have been widely adopted for windblown sand control and mitigation along railways. However, the inclination angles of inserting the concrete plate with respect to the vertical direction, i.e., straight or obliquely inserted concrete plates (SIP or OIP), significantly influence the efficiency of sand-control. This study performs a comparative evaluation of the SIP and OIP sand-control fences using wind tunnel testing and field monitoring data collected from the Lanzhou-Wulumuqi High-Speed Railway Project. The results show that the fence's ability to reduce the wind speed and the sand-retaining efficiency gradually weakens with the increasing wind speed. Compared with the SIP fence, the OIP fence has a better wind speed reduction capability, stronger ability to capture fine particles below the top of the fence; it is more efficient for sand-retaining and induces stronger eddy intensity. Generally, the wind tunnel test and field monitoring results are consistent, whereas wind tunnel tests incline to overestimate wind speed reduction and sandcontrol efficiency. The study also finds that the aeolian sand accumulated around the fence can weaken the protection efficiency, and hence cleaning the aeolian sand
\end{abstract}

Dongyuan Wang

Dongyuan.wang@gmail.com;

Dongyuan.wang@swjtu.edu.cn

1 School of Civil Engineering, Southwest Jiaotong University, Chengdu 610031, China

2 Key Laboratory of High-Speed Railway Engineering, Ministry of Education, Southwest Jiaotong University, Chengdu 610031, China

3 Northwestern Research Institute Co., Ltd., China Railway Engineering Corporation, Lanzhou 730000, China accumulated around the fence should be done periodically to ensure the designed functions.

Keywords Concrete-plate fences $\cdot$ Plate-inserting methods - Sand-control performance evaluation - Wind-sand flow . Wind tunnel test · Field monitoring

\section{Introduction}

Aeolian sand along railway and highway lines caused by wind-sand flow has potential risks for safety. Sand-control systems, usually sand-control fences, are typically installed to reduce such risks, e.g., the Taklamakan desert highway $[1,2]$, the Qinghai-Tibet railway [3, 4], and the BaotouLanzhou railway [5]. The Lanzhou-Wulumuqi high-speed railway (LWHR), which is the world's first high-speed railway through the vast strong wind areas in the Gobi desert [6] with a design speed of $250 \mathrm{~km} / \mathrm{h}$ and a total length of $1776 \mathrm{~km}$ from Lanzhou to Wulumuqi in the northwestern part of China, mainly adopted sand-control fences to intercept the sand particles on the predominant wind direction side $[6,7]$. Considering the durability and the ability to resist wind forces, most of the sand-retaining fences adopted along LWHR are made of concrete but with different inclination angles of inserting-plate with respect to the vertical direction, i.e., straight-installed plates (SIP, as shown in Figs. 1a, 2a) and oblique-installed plates (OIP, as shown in Figs. 1b, 2b), both the SIP and OIP fences are designed as porous fences to enhance the sand-control efficiency [8]. 
The aerodynamic and sand-control performance of the fences depends on its geometric design, mainly including fence porosity, fence height, the relative wind direction, as well as porosity structure feature [9]. Fence porosity is commonly considered the most important parameter controlling the protective performance of the fences; however, it seems that the optimal porosity lacks consistency in research. Raine and Stevenson [10] believed that a fence with a porosity of $20 \%$ has the best reduction in leeward mean velocity. Perera et al. [11] deemed that solid fences are best for protecting the near-wake zone, while a fence with a porosity of $20 \%$ provides good shelter characteristics in the far wake. Lee et al. [12] found that the fence with a porosity of $30 \%$ has a good shelter effect for alleviating windblown sand particles, while Dong et al. [13] recommended an optimal value of $30 \%-40 \%$. From the perspective of mechanics, Dong et al. [14] revealed that the
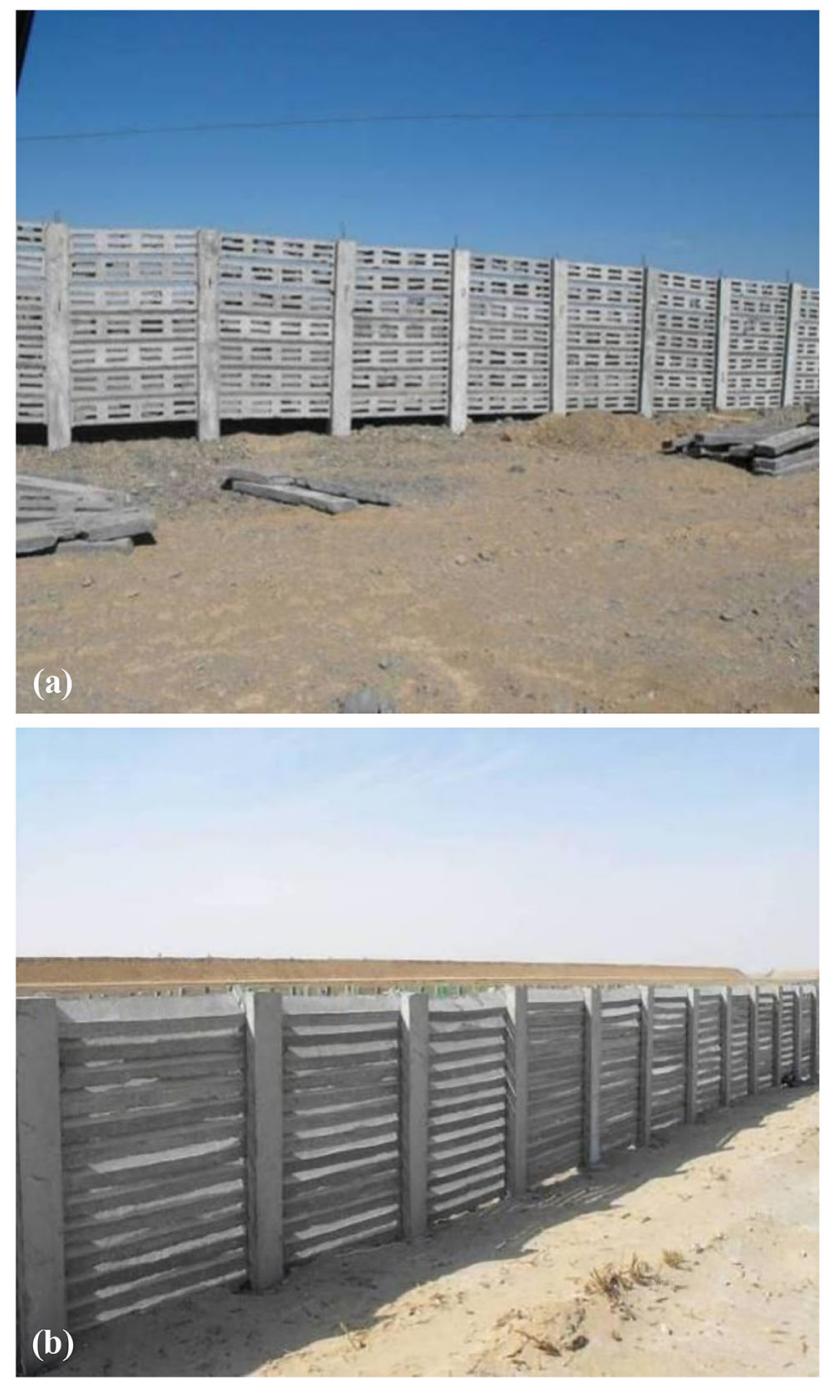

Fig. 1 Photographs of inserting-plate sand-retaining fences: a SIP and $\mathbf{b}$ OIP critical fence porosity is about $30 \%$. As for fence height, Caborn [15] indicated that the range of the downwind shelter zone is proportional to the fence height, and Alhajraf et al. [16] confirmed that the sand-trapping potential is usually controlled by the fence height. Ceteris paribus, the shelter distance of the fence is negatively correlated with the relative wind direction referring to the angle between the incoming wind direction and the normal of the fence orientation. Jacobs [17] found that the recovery distance required by the wind flow to re-reach the mean wind speed or turbulence intensity in the open field decreased with an increase in the relative wind direction. Using field monitoring data, Wilson [18] found the obliquity of the approaching wind may reduce the actual shelter distance of the fence, which was also proven by Peña et al. [19]. Concerning the structure feature of the porosity, there is little data in the literature available, especially field monitoring data, supports the consensus conclusion on which type is relatively effective for a certain height and porosity. Unfortunately, the SIP and OIP fences encountered the same problem for the LWHR project, though some relevant studies provided insights and helped to understand the influence of porosity structure feature on the protection effect [20-22]. The main concern is that the fences mentioned above lack in situ monitoring data to verify the reliability of the wind tunnel results, and the porosity structure used in the research is also different from the OIP and SIP fences that the LWHR intended to use. Moreover, the inclination angle of the inserted plates with respect to the vertical direction may induce different aerodynamic performance and affect the sand-control efficiency of the fence.

Three methods are often used to study windblown sand problems mentioned above. Firstly, numerical simulation is widely used to investigate the flow characteristics around the fence. For instance, Telenta et al. [23] analyzed the bar inclination effect on the fence wake characteristics behind the fence using the three-dimensional numerical model, and found that the bleed flow gets stronger and the turbulence intensity decreases with the bar inclination angle decreasing [23]. Lima et al. [24] investigated the factors controlling the fraction of soil area over which the basal average wind shear velocity drops below the threshold for sand transport, and found that for typical sand-moving wind velocities, the optimal fence height which is in a costefficient view is around $50 \mathrm{~cm}$. Bruno et al. [25] compared the aerodynamic behavior of different solid barriers and estimated the sand sedimentation performance of each barrier using an approximated metric related to shear stress. Their results showed that the patented S4S barrier has the best sedimentation performances due to its innovative aerodynamic shaping. Secondly, the wind tunnel test, i.e., a scale physical model, is also a powerful tool to study the 
aerodynamic characteristics of fences under artificially simulated atmospheric boundary conditions. This method has recently been more used to study the effect of fence protection. Dong et al. [26] analyzed the inherent link between fence porosity and mean airflow characteristics behind the fence, and confirmed that the optimal porosity is around 0.2 or 0.3 . Zhang et al. [27] investigated the shelter effect of a porous wind fence (porosity $=38.5 \%$ ) on saltating sand in a simulated atmospheric boundary layer. They found that the mean speed decrease obviously on the leeward of the fence, and a high-speed area exists in the shear layer above the fence. In addition to the above two research methods, field monitoring (i.e., the full-scale physical model) is the most valuable as well as the most costly tool to study the aerodynamic characteristics of the fences in the field. Cheng et al. [28] evaluated the sandcontrol efficiency of various fences along the QinghaiTibet railway and analyzed their advantages and disadvantages. Zhang et al. [29] analyzed the windproofing and sand-fixing benefits of different specifications of straw checkerboards and their impact on ecological restoration. They found that a one-meter-long checkerboard had the best performance at reducing the surface wind speed and intercepted sand. Compared with numerical simulation and wind tunnel tests, field monitoring needs a much longer time and is less adopted in research. However, Alhajraf [16] found that solely using numerical simulation or wind tunnel tests may lead to an insufficient understanding of the sand-control performance of the fence due to different boundary conditions and wind-sand environments. Therefore, there is a need to conduct research to compare the differences among the above three methods.

It has been noted that there have been few sand-control fences in situ experiments associated with sand transport study presumably due to the complexity of solid-air interactions on wind-sand flow and the high investment of longterm monitoring. Our literature review indicates that most of the research results mentioned above have not been applied in actual projects, and the research conclusions are not verified with field monitoring data. In practice, the SIP fences have been used in Qinghai-Tibet Railway with a low wind speed environment, where the maximum wind speed is approximately $25 \mathrm{~m} / \mathrm{s}$ [3], which is significantly lower than that of about $60 \mathrm{~m} / \mathrm{s}$ along with the LWHR project $[7,21]$. The magnitude of wind speed may affect the sand-carrying capacity of airflow and thus influence the sand-control performance of the fence; i.e., theoretically, relatively high wind speeds may induce most sand grains to deposit only on the leeward side of the fence. In addition, the OIP fences were first used in real engineering practice, and its sand-control performance needs to be verified.

Although both the SIP and OIP fences are porous, Bruno et al. [30] still divided them into two categories according to the different sedimentation mechanisms that they derived and the aerodynamic performance, e.g., fence with localized porosity and fence with deflecting porosity. Moreover, research comparing the sand-control for different fences to help fence selection in practice to control and mitigate aeolian sand hazards is limited. To better understand the sand-control performance of fences and the windsand flow field properties around the fence, this study comparatively evaluates the sand-control performance of the SIP and OIP fences using field monitoring data of sand transport and wind tunnel tests.

\section{Wind tunnel test}

\subsection{Apparatus and materials}

The wind tunnel utilized in this study has a total length of $38 \mathrm{~m}$ and is mainly comprised of five parts: the power section, the rectifier section, the sand supply section, the test section, and the diffusion section. In the sand supply section, the sand samples were laid flat at the bottom of the wind tunnel and would move when the incoming wind speed exceeds the threshold wind speed. The test section has a square shape of $1.2 \mathrm{~m} \times 1.2 \mathrm{~m}$ with a length of $21 \mathrm{~m}$. The inlet wind speed in the wind tunnel can be adjusted within the range of $0-40 \mathrm{~m} / \mathrm{s}$.

It is well known that the accuracy of wind tunnel test results is closely related to the simulation of the atmospheric boundary layer, a thin layer with an obvious velocity gradient mainly affected by the surface friction, in which the flow is mainly turbulent. To ensure the accuracy of test results, the passive method was used to simulate the boundary layer in the wind tunnel. The emery paper was used to simulate the roughness of elements, and the paper adhered to the bottom of the wind tunnel $40 \mathrm{H}-60 \mathrm{H}$ away from the windward side of the fence model, where $H$ is the fence height.

During testing, the wind speed at different monitoring points was measured with the pitot tubes, as illustrated in Fig. 3a. The pitot tubes, which can simultaneously monitor the speed at heights of $0.3,0.5,1.0,1.5,3.0,6.0,12.0,20.0$, 35.0 , and $50.0 \mathrm{~cm}$, were arranged at the locations of $10 \mathrm{H}$, $5 \mathrm{H}, 2 \mathrm{H}, 1.0 \mathrm{H}$ and $0.5 \mathrm{H}$ away from the windward side of the fence, and $0.5 H, 1 H, 2 H, 5 H, 10 H, 15 H$ and $20 H$ away from the leeward side of the fence, respectively.

The sand transport rate in the wind-sand flow was determined by the vertical distribution of the sand mass collected by the stepped sand collection boxes, as shown in Fig. 3b. The stepped sand collection box includes ten sand samplers. Each sampler has a cross section of $2 \mathrm{~cm} \times 2 \mathrm{~cm}$ and is arranged $2 \mathrm{~m}$ away from the leeward side of the fence model. The central heights of the sand sampler 
(a)

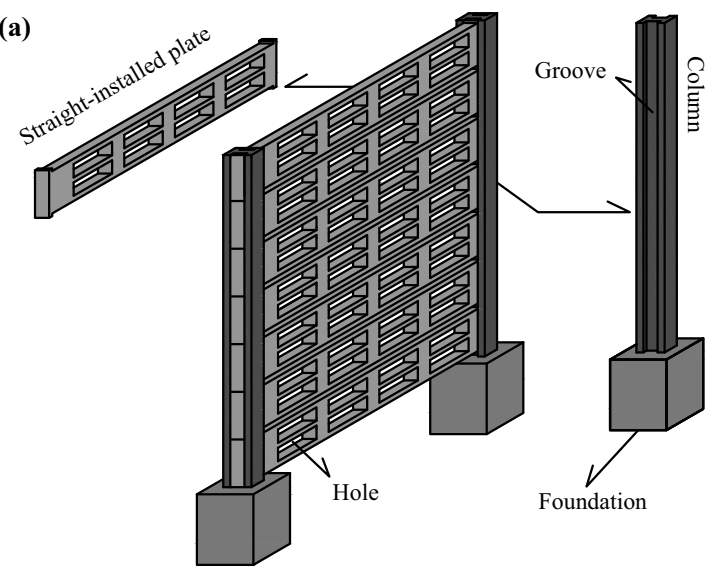

(b)

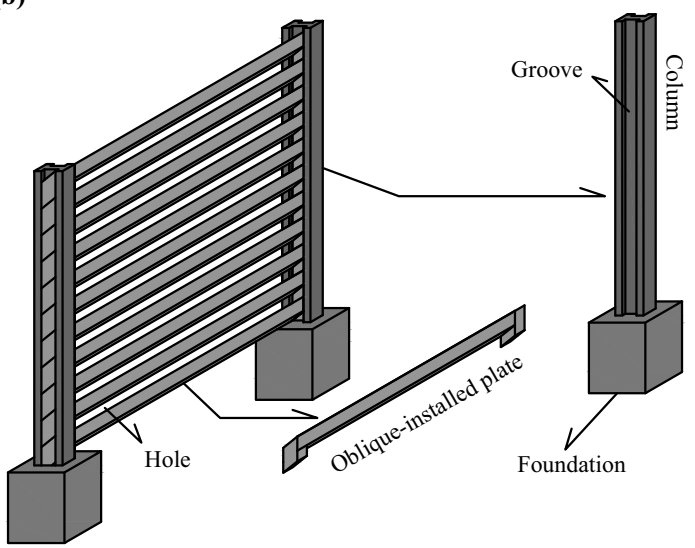

Fig. 2 Schematic diagram of the fence structure: a SIP and b OIP

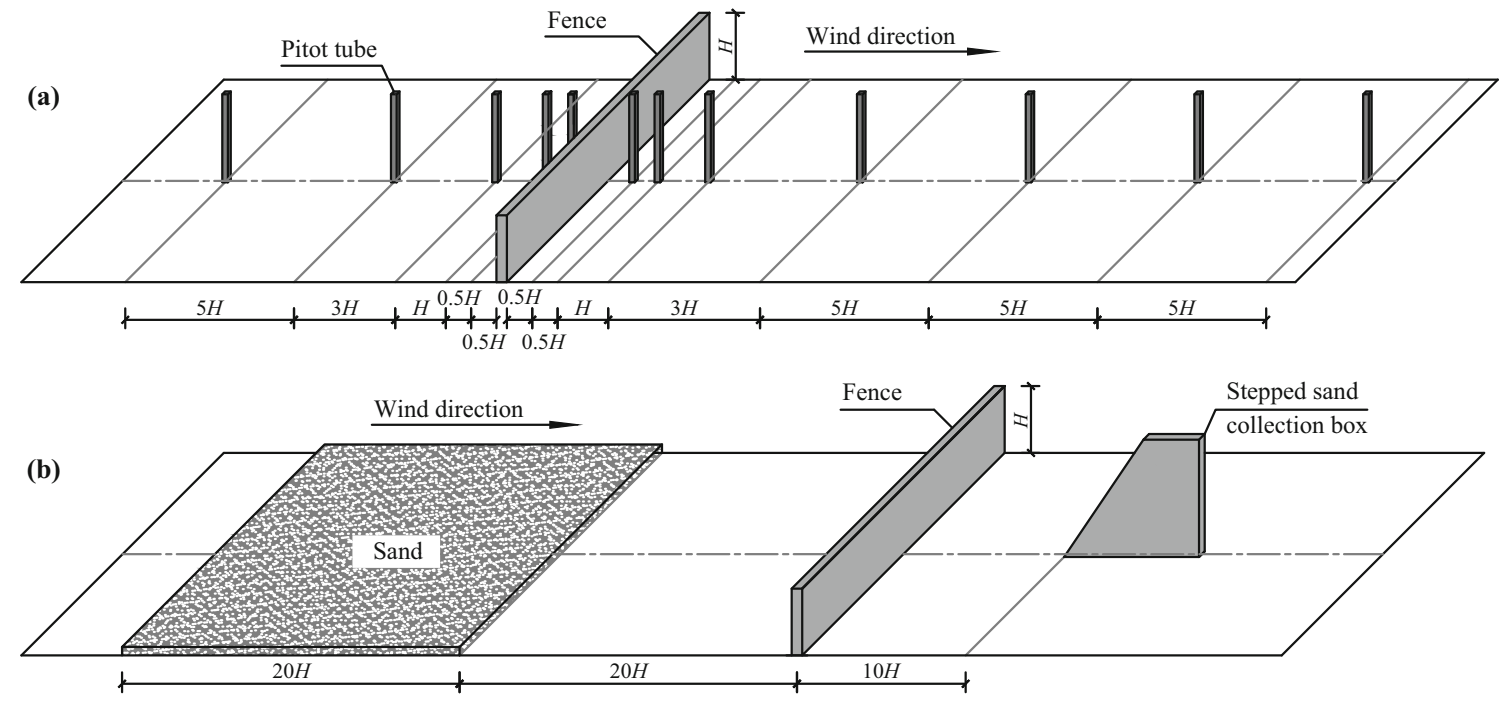

Fig. 3 Layout of the test section of the wind tunnel: a measuring wind speed and $\mathbf{b}$ measuring sand flux density

installed within the stepped sand collection box are 1, 3, 5, $7,9,11,13,15,17$, and $19 \mathrm{~cm}$ from the wind tunnel bottom. The sand samples used in the wind tunnel were taken from the field monitoring site, and the grain composition is shown in Fig. 4.

\subsection{Similarity discussions}

The movement characteristics of the airflow in the field are so complicated that it is very challenging to simulate the behavior accurately with wind tunnel tests. However, geometric similarity, kinematic similarity, and dynamic similarity of a wind tune test can enhance the reliability of the experimental data.

Geometric similarity mainly refers to the similarity in size and shape between the model and the real fence used in the actual project. The SIP or OIP fences along the LWHR have a typical height of $2.0 \mathrm{~m}$ and a typical porosity of approximately $20 \%$; multiple plates are inserted using an inclination angle of $0^{\circ}$ for SIP and $45^{\circ}$ for OIP, respectively. Wooden strips were used in the wind tunnel test to model the fences, and the heights of the models were set to $0.2 \mathrm{~m}$, with a geometric similarity ratio of $1: 10$. The width of the models was $1.2 \mathrm{~m}$, which is equal to the cross section width of the wind tunnel. Furthermore, the shape of each component of the fence was approximately replicated and reduced following the above proportion. The porosity of the models was designed as the same as the real fences, i.e., approximately $20 \%$. Theoretically, the blockage ratio of the wind tunnel should be less than $5 \%$ to avoid distortion effects, but $16.7 \%(=0.2 / 1.2)$ of the blockage ratio is used in this study due to limitations of the wind tunnel 


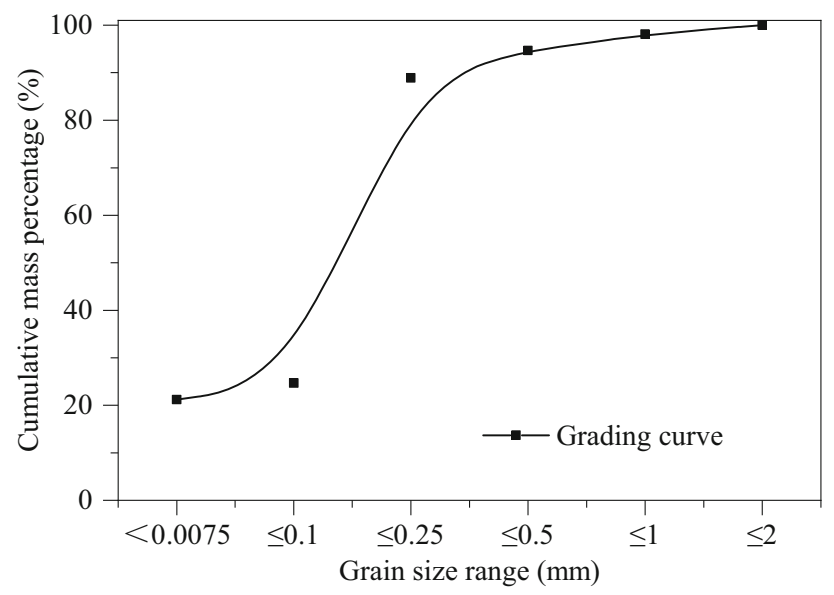

Fig. 4 Grading curve of wind-sand flow in the monitoring site

facility and porous fences will affect the airflow less than solid objects [31].

Equation (1) is used to ensure the similarity of the wind speed profile [32], which is a key factor of the kinematic similarity:

$U_{Z} / U_{Z_{r}}=\left(Z / Z_{r}\right)^{\alpha_{i}}$,

where $U_{Z}$ and $U_{Z_{r}}$ are the mean wind speed values at heights $Z$ and $Z_{r}$ from the ground in the field or the laboratory wind tunnel, respectively; $\alpha_{i}$ is the wind speed profile index, also known as the surface roughness index. The roughness index in the field was calculated to be 0.113 using $U_{200}$ and $U_{30}$, and the roughness index in the wind tunnel test was calculated to be 0.107 using $U_{20}$ and $U_{3}$. The two values of $\alpha_{i}$ are approximately equal, indicating that wind speed profiles in the field and wind tunnel both conform to the power-law exponent and thus the wind tunnel test can be regarded as satisfying the movement similarity [32].

The similarity of Reynolds numbers (Re) typically represents the kinematic similarity, but it was also used to measure the dynamic similarity for the wind tunnel test [32]. The reduction in the experimental model results in that the $R e$ of the wind tunnel is several times smaller than that in the field. Previous studies have shown that scaled model flows will be dynamically similar to the full-scale case if $\mathrm{Re}$ is equal to or greater than the minimum independence value of $1 \times 10^{5}$ [33]. For the wind tunnel test in this study, the calculated Re value ranges from $4.15 \times 10^{5}$ to $10.37 \times 10^{5}$, implying that the wind tunnel test essentially meets the required dynamic similarity. Note that when calculating the Re value in this study, the formula $R e=\rho v l / \mu$ is used, where $\rho$ denotes the airflow density and equals $1.103 \mathrm{~kg} / \mathrm{m}^{3} ; v$ is the mean the airflow speed and takes the values of 10,18 , and $25 \mathrm{~m} / \mathrm{s}$, respectively; $l$ is the characteristic length and equals $0.677 \mathrm{~m}$; and $\mu$ is the

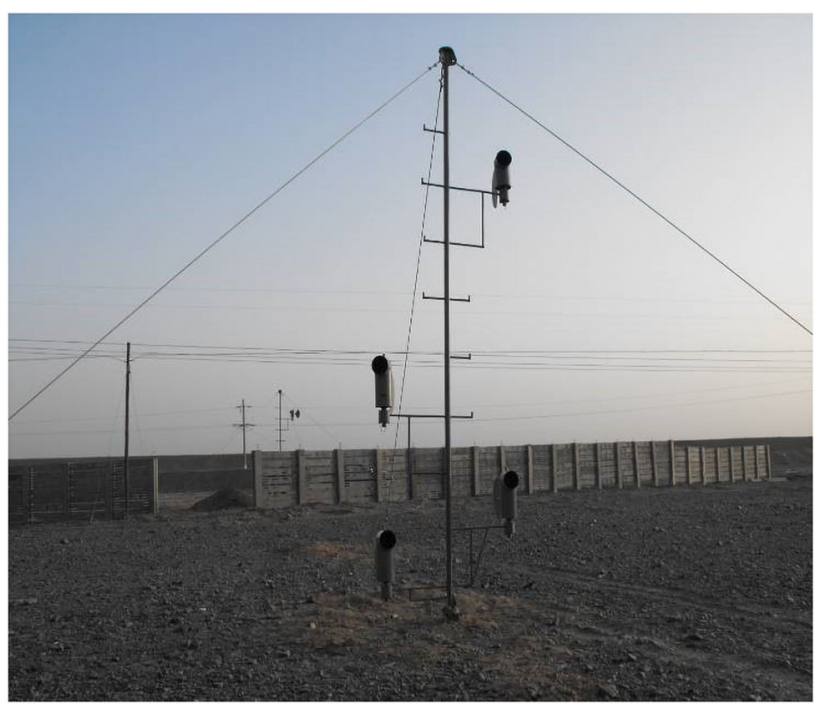

Fig. 5 Spin-type sand collecting instruments along the LWHR

dynamic viscosity of airflow, which equals $1.80 \times 10^{-5} \mathrm{~Pa} \cdot \mathrm{s}$.

\section{Field monitoring}

The wind tunnel test described above was used to initially evaluate the sand-control performance of the fences during the preliminary design phase before the actual fences have been installed along the LWHR. Furthermore, a field monitoring program was carried out after installation of the actual fences to verify the reliability of the wind tunnel test.

The field monitoring site, located in the Yandong wind area along LWHR, is covered mostly by the Gobi desert landscape. The instantaneous maximum wind speed in this area can reach $42.3 \mathrm{~m} / \mathrm{s}$ [34] (note that this speed is not the maximum wind speed of $60 \mathrm{~m} / \mathrm{s}$ yet that the LWHR exposes). However, the Yandong wind zone is abundant sand sources, so the wind-sand activity is very intense; and the strong wind in this area has a high potential to cause severe wind-sand disasters. The sand-control effects of the fences were monitored on-site using the spin-type sand collecting instrument. This instrument comprises a reinforced concrete foundation that supports a steel pipe column with sand samplers tied to the column. The sand samplers can rotate freely with the wind force to ensure that the inlet is always in line with the wind direction, which improves the accuracy of the monitoring results. The steel column made the sampler capable of collecting sands flown in high locations.

As shown in Fig. 5, the spin-type sand collecting instrument used in the LWHR includes four sand samplers with four circular-opening inlets, which are installed at 0.5 , $1.0,2.0$, and $4.0 \mathrm{~m}$ above the ground surface, respectively. 


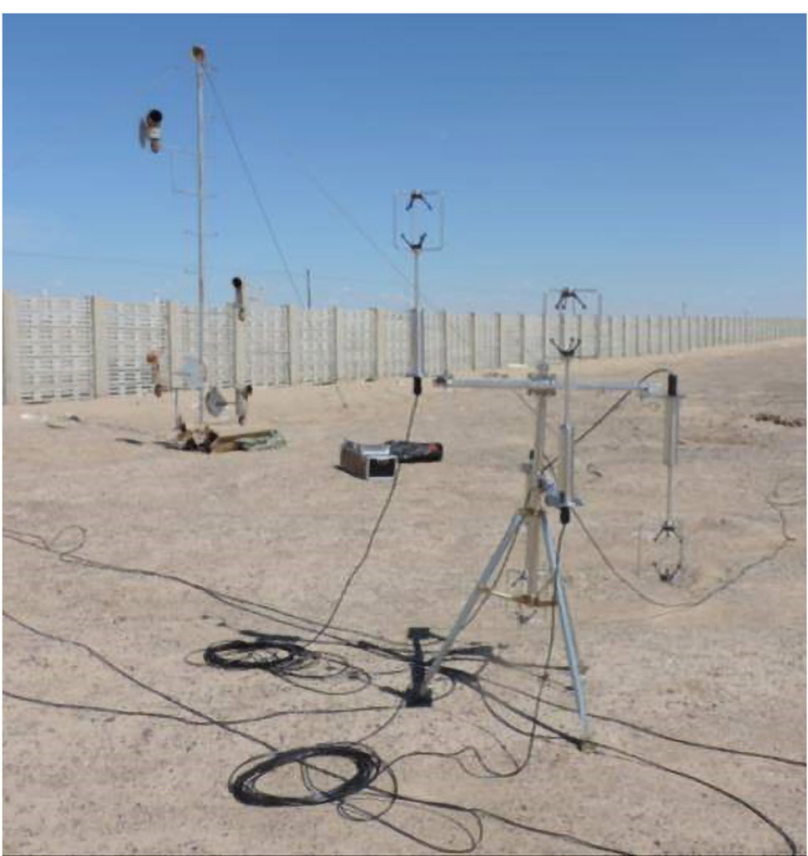

Fig. 6 Wind Master Pro 3D anemometer for measuring wind speed around fences

To monitor the vertical mass distribution of sands in the wind-sand flow on both sides of the fence, a set of sand collecting instruments are installed at $50 \mathrm{~m}$ windward and $20 \mathrm{~m}$ leeward from the sand-control fence, respectively. The monitoring data were collected after each gale day during the 2 years of carrying out the field monitoring program.

The wind speed at different horizontal positions on both sides of the fence was measured simultaneously by the GILL WindMaster Pro 3D anemometer (Fig. 6), which can measure the wind speed ranging from 0 to $65 \mathrm{~m} / \mathrm{s}$ with the wind direction ranging from 0 to $359^{\circ}$. Each fence has a monitoring section, and each monitoring section has a total of 5 anemometers, installed at 20.0,10.0, and $3.0 \mathrm{~m}$ from the fence on the windward side, and 3.0 and $20.0 \mathrm{~m}$ from the fence on the leeward side, respectively, and each anemometer contains 1 wind speed sensor installed at $1.2 \mathrm{~m}$ (i.e., $0.6 H$ ). To obtain the wind speed profile in the study area, the vertical distribution of wind speed at $50 \mathrm{~m}$ from the fence on the windward side was also measured by the GILL WindMaster Pro 3D anemometer, and the height of monitoring points were installed at $30,60,150$, and $200 \mathrm{~cm}$ above the ground surface, respectively.

\section{Results}

\subsection{Results of wind tunnel tests}

\subsubsection{Airflow field structure}

Figure 7 shows the contour map of wind tunnel tests obtained using the Kriging method in the Surfer 11.0 software under different wind speeds with 120 points of wind speed data around the two types of fences, where $L$ is

$\begin{array}{lllllllllllll}10 & 9 & 8 & 7 & 6 & 5 & 4 & 3 & 2 & 1 & 0 & \text { Wind direction }\end{array}$
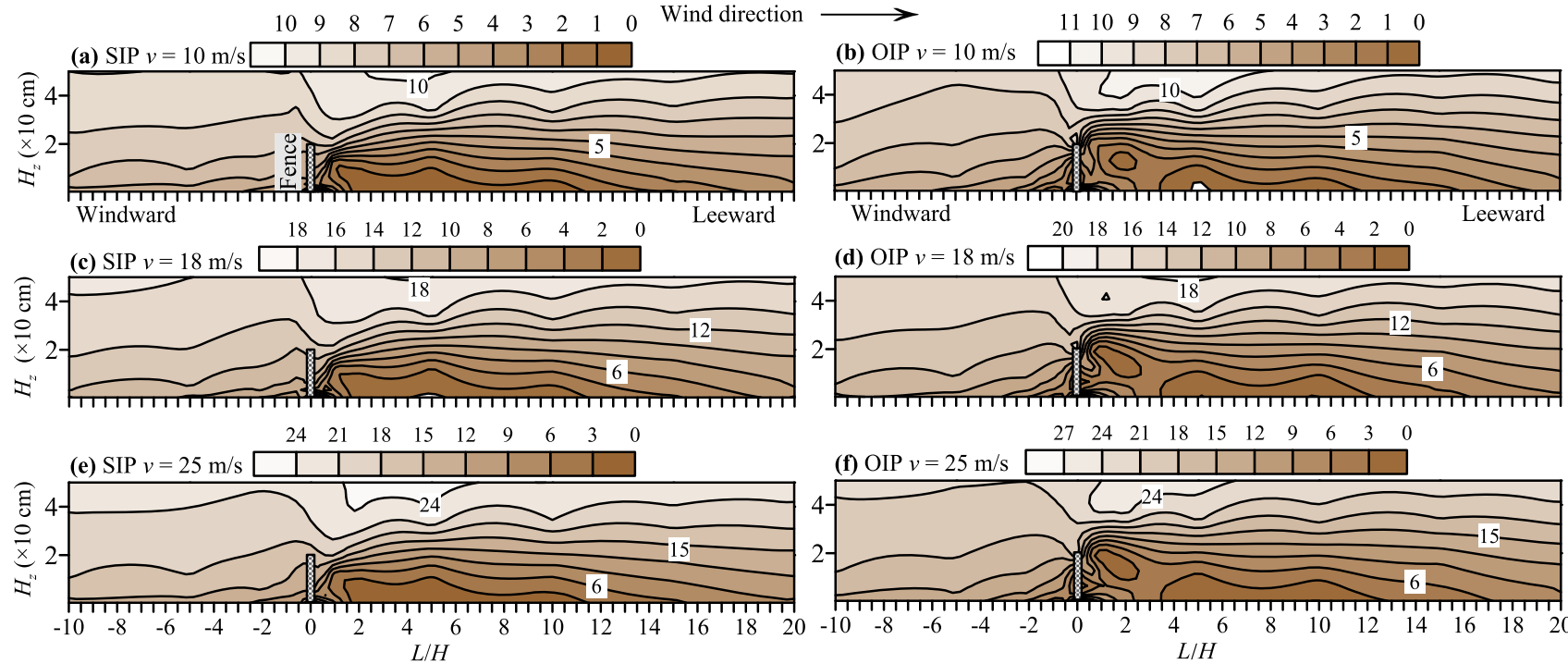

$\begin{array}{llllllllll}27 & 24 & 21 & 18 & 15 & 12 & 9 & 6 & 3 & 0\end{array}$

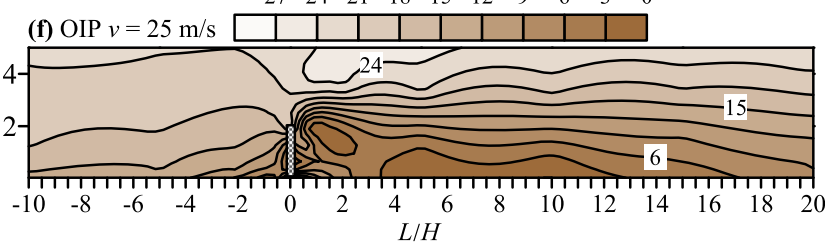

Fig. 7 Contours of the wind speed around fences based on wind tunnel test: $\mathbf{a} v=10 \mathrm{~m} / \mathrm{s}$ for SIP, $\mathbf{b} v=10 \mathrm{~m} / \mathrm{s}$ for OIP, $\mathbf{c} v=18 \mathrm{~m} / \mathrm{s}$ for SIP, d $v=18 \mathrm{~m} / \mathrm{s}$ for OIP, e $v=25 \mathrm{~m} / \mathrm{s}$ for SIP, and $\mathbf{f} v=25 \mathrm{~m} / \mathrm{s}$ for OIP (unit: $\mathrm{m} / \mathrm{s} ; v$ represents the inlet wind speed of the wind tunnel; $H_{z}$ represents the height above the bottom of wind tunnel) 

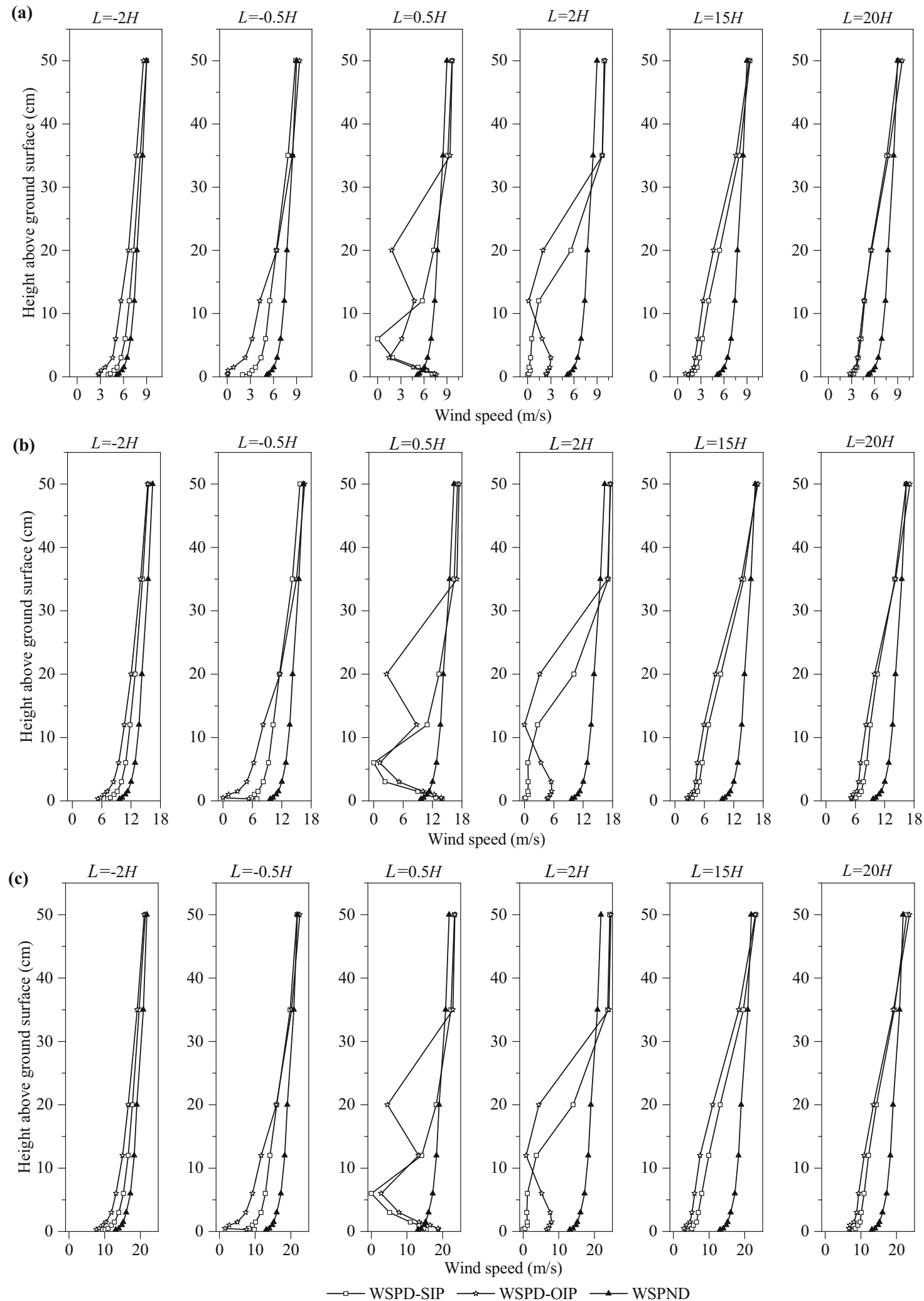

Fig. 8 Comparison between the wind speed profile disturbed by the fence and that not disturbed by the fence at different inlet wind speeds: a $v=10 \mathrm{~m} / \mathrm{s}, \mathbf{b} v=18 \mathrm{~m} / \mathrm{s}$, and $\mathbf{c} v=25 \mathrm{~m} / \mathrm{s}$. The WSPD-SIP and WSPD-OIP represents the wind speed profile disturbed by the SIP and OIP fence, respectively 

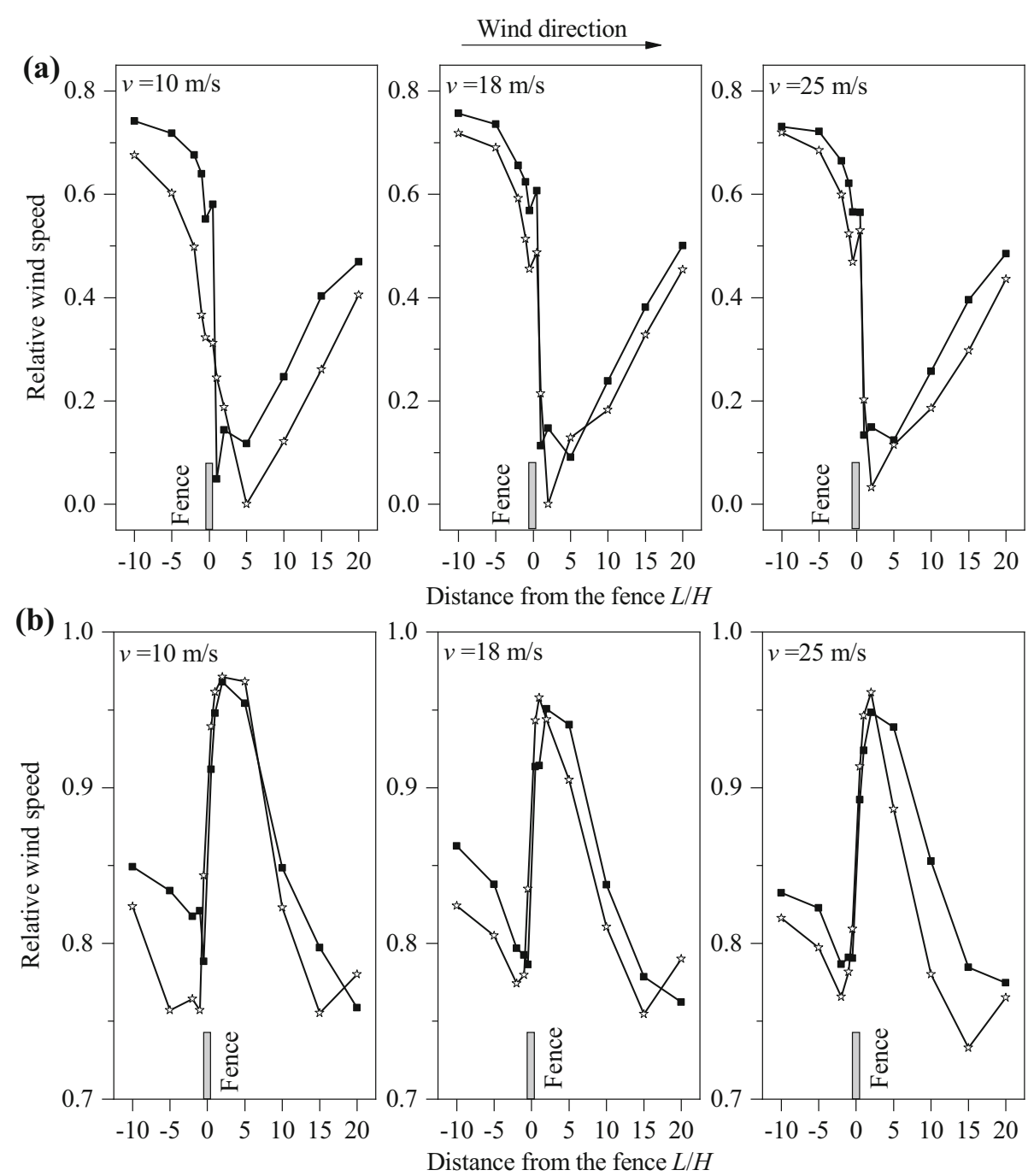

$\longrightarrow$ SIP $\leadsto$ OIP

Fig. 9 The relative wind speed around fences at different inlet wind speeds based on wind tunnel tests: a at a height of $0.6 H$ above the bottom of wind tunnel, and $\mathbf{b}$ at a height of $1.75 \mathrm{H}$ above the bottom of wind tunnel

the distance from the fence model and its negative and positive values represent points on the windward side and the leeward side, respectively. Similar to [21], the wind field around the fence (Fig. 7) can be roughly divided into three zones according to the wind speed and formation mechanism: the local acceleration zone, the deceleration zone on the windward side below the top of the fence, and the wake zone on the leeward side of the fence below the top of the fence. The local acceleration zone above the top of the fence is caused by the Venturi effect, the deceleration zone is caused by the retarding effect of the fence, and the wake zone is caused by the eddy and the adverse pressure gradient. It is worth noting that there are two eddies in the wake area of the OIP fence and one eddy in the SIP fence due to the difference in pore structure, indicating that the eddy intensity in the wake area of the OIP fence is stronger than that of the SIP fence. Thus, the wake area of the OIP fence has a stronger sand capture capability.

\subsubsection{Variation of wind speed profile around the fence}

The comparison between the wind speed profile disturbed by the fence (WSPD) and that not disturbed by the fence (WSPND) under inlet wind speeds of 10, 18 and $25 \mathrm{~m} / \mathrm{s}$ are shown in Fig. 8a-c, respectively. For the same fence, the WSPD at the same horizontal position is similar under three inlet wind speeds. It is also observed that for the same fence, the WSPND is analogous to that of the WSPD at $L=-2 H,-0.5 H, 15 H$ and $20 H$, showing a logarithmic 


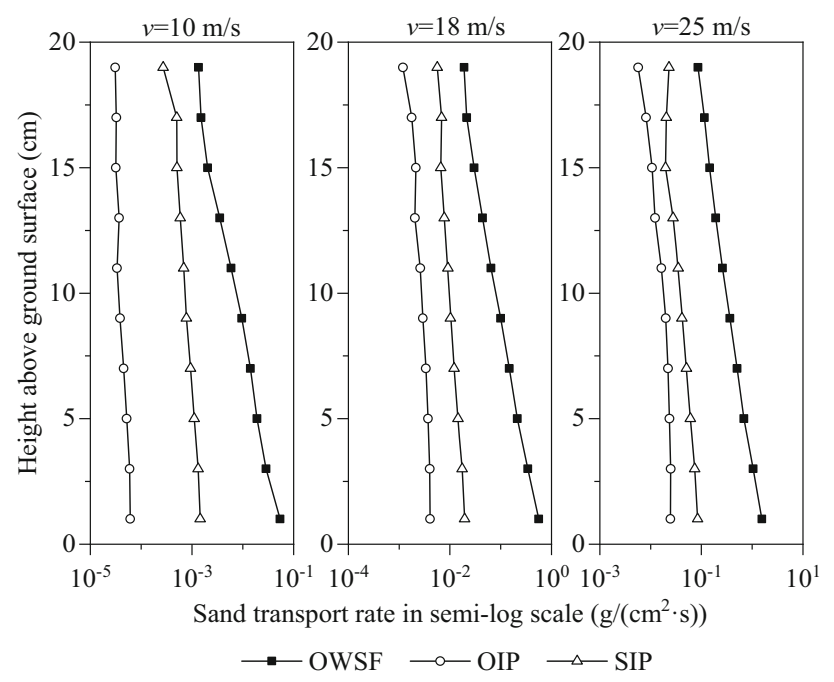

Fig. 10 The vertical distribution of the sand transport rate under different conditions based on wind tunnel tests. OWSF represents the sand transport rate of the original wind-sand flow with no fences; SIP and OIP represent the sand transport rate at the leeward side of the SIP fence and OIP fence, respectively

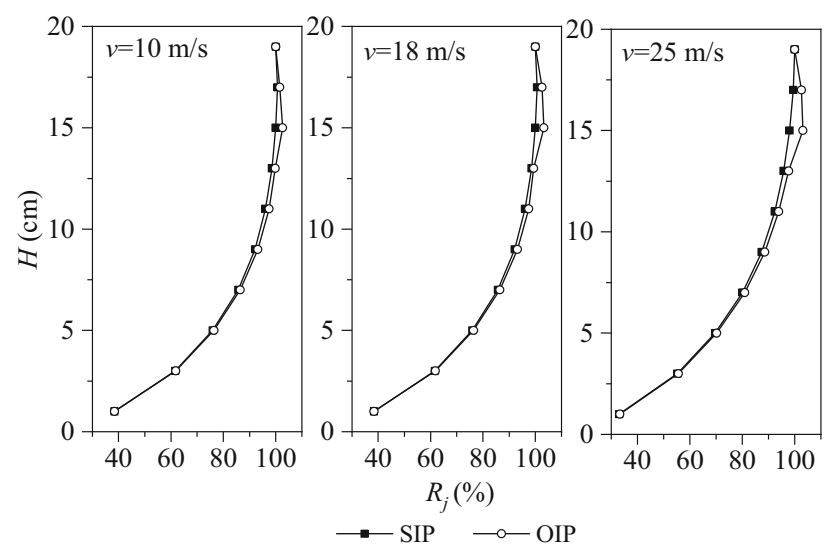

Fig. 11 Cumulative sand-retaining rates under different wind speeds based on wind tunnel tests: a $v=10 \mathrm{~m} / \mathrm{s}, \quad$ b $v=18 \mathrm{~m} / \mathrm{s}$, and c $v=25 \mathrm{~m} / \mathrm{s}$

distribution law with height, but different from that of the WSPD at $L=0.5 H$ and $2 H$ which shows obvious wave-like distribution, especially below the top of the fences. The observation indicates that the eddy intensity in this area is strongly affected by the uneven pores. Moreover, the WSPD on the leeward of the fences is different from that of Lee et al. [35], where the variation trend of the WSPD at $L=0.5 H$ and $2 H$ below the top of the fences with height is relatively more uniform. The findings indicate that although the pore structure does not affect the wind field around the fence as effectively as the porosity, the protection efficiency of fences can be further improved by adjusting the pore structure given the same porosity.

The comparison of wind speed profiles at different positions shows that the wind speed is significantly reduced below the top of the fences and slightly increased above the top. Compared with the SIP fence, the OIP fence is more efficient to reduce the wind speed below the top of the fence but accelerates the speed above the top. It is found that the WSPD on the leeward deviates further from the WSPND than that on the windward, which reflects indirectly that the leeward side of the fence has a better wind speed reduction effect.

\subsubsection{Relative wind speed}

Except for the scope of the deceleration zone and wake zone, the attenuation amplitude of wind speed around the fence, which can be represented by the relative wind speed, is also a key index to indirectly evaluate the sand-control performance. The relative wind speed at a given height $z$ above the ground is referred to as the ratio of the wind speed disturbed by the fence at height $z$ to the inlet wind speed at height $z$ not disturbed by the fence. The relative wind speed, $K_{z}$, can be calculated using Eq. (2) [36]:

$K_{z}=v_{z} / v_{z 0}$,

where $K_{z}$ is the relative wind speed (\%) at height $z, v_{z}$ is the wind speed (in $\mathrm{m} / \mathrm{s}$ ) disturbed by the fence at the height $z$, and $v_{z 0}$ is the inlet wind speed (in $\mathrm{m} / \mathrm{s}$ ) not disturbed by the fence at the height $z$.

As shown in Fig. 9, the variation trend of the relative wind speed around the two types of fences at a similar height is similar for three inlet wind speeds (i.e., 10, 18, $25 \mathrm{~m} / \mathrm{s}$ ). It is found that the variation trends of the relative wind speed above and below $H$ are markedly different. As Fig. 9a shows, the relative wind speed at $0.6 H$ from the bottom of the wind tunnel follows an approximate v-shaped distribution with a minimum value near the fence, while Fig. 9b shows that the relative wind speed at $1.75 \mathrm{H}$ from the bottom of the wind tunnel presents an approximately $\mathrm{w}$-shaped distribution with a maximum value near the fence. In addition, it is noted that for the same fence, the relative wind speed above $H$ is significantly higher than that below $H$, and the horizontal length for less than a certain relative wind speed on the leeward side is much larger than that on the windward side when the height is below $H$, as shown in Fig. 9a. The above observations imply that the protection range of the fence is within its height $\mathrm{H}$, the sand particles in wind-sand flow are more easily deposited on the leeward side, and the area of depositing sand is also larger.

The following differences can be found by comparing the relative wind speed of the two types of fences at 


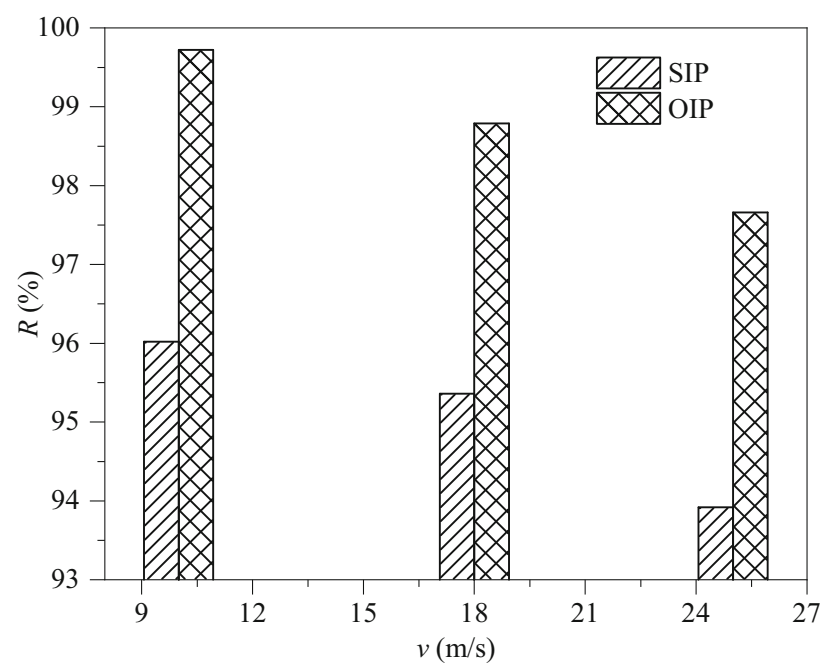

Fig. 12 Total sand-retaining rate under different wind speeds based on wind tunnel tests

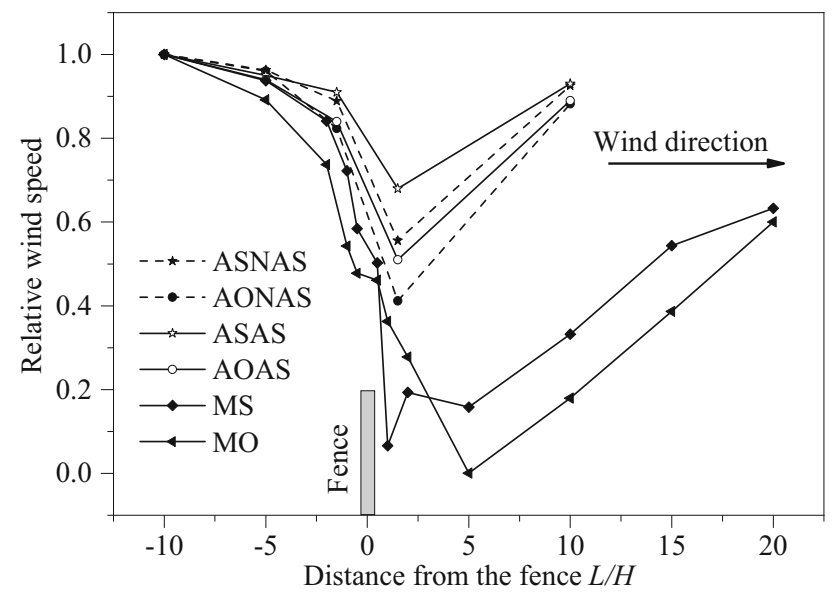

Fig. 13 Comparison of the relative wind speed around fences at the inlet wind speed of about $10 \mathrm{~m} / \mathrm{s}$ based on field monitoring and wind tunnel test. The monitoring height is $0.6 H$. ASNAS, AONAS, ASAS, AOAS, MS, and MO represent the actual SIP with no aeolian sand, actual OIP with no aeolian sand, actual SIP with aeolian sand, actual OIP with aeolian sand, model SIP, and model OIP, respectively

different wind speeds: (1) At a height less than $H$ (Fig. 9a), the relative wind speed curve of the OIP is generally below that of the SIP under the same wind speed and the gap between the two curves decreases gradually with wind speed increasing. (2) At a height greater than $H$ (Fig. 9b), the relative wind speed of the OIP is also smaller than that of the SIP under the same wind speed except for the location near the fence on the leeward side. Furthermore, with an increase in the wind speed, the gap between the two on the windward side decreases gradually, while the gap on the leeward side increases gradually.
The above phenomenon indicates that the OIP fence has stronger capabilities than the SIP fence in terms of reducing the wind speed under the same wind speed. The gap between the two fence's ability to reduce the wind speed decreases gradually with an increase in the wind speed. Another observation is the ability of the OIP fence to accelerate airflow at the top of the fence is stronger than that of the SIP fence. Acceleration in airflow may increase the number of sand particles crossing the fence and weaken the sand-control capability. However, this phenomenon is only observed at the top of the OIP fence, which has little impact on protection efficiency.

\subsubsection{Sand transport rate on both sides of the fence}

The transport rate is an indicator of the airflow capacity of transporting sand. When the wind-sand flow passes through the fence, most of the particles can deposit around the fence due to the local wind speed reduction and airflow recycling, thus the transport rate of the wind-sand flow will decrease. Hence, its variation on either side of the fence can reflect the fence's ability to purify the wind-sand flow. Based on the data obtained from the wind tunnel tests, the sand transport rate of the wind-sand flow can be calculated according to Eq. (3) [37]:

$F_{z}=M_{z} /\left(A_{z} \times T\right)$,

where $F_{z}$ is the sand transport rate (in a unit of $\mathrm{g} /\left(\mathrm{cm}^{2} \cdot \mathrm{s}\right)$ ) at a certain height; $M_{z}$ is the mass of sand particles at the height collected by the sand sampler in $T$ periods $(\mathrm{g}) ; A_{z}$ is the inlet area of the sand sampler $\left(\mathrm{cm}^{2}\right)$; and $T$ is the duration of wind speed (s).

As shown in Fig. 10, the sand transport rate of the original wind-sand flow undisturbed by the fence follows an approximate linear distribution on a semi-logarithmic scale with varying height for different inlet wind speeds, and the sand transport rate under no fence condition is very sensitive to the height and the wind speed. Therefore, reducing the wind speed will very efficiently reduce the sand transport rate in the airflow. Comparing the sand transport rate with and without fences under different wind speeds (Fig. 10), we can see that the sand transport rate decreases sharply after the original sand flows through the fence. Moreover, the sand transport rate with the OIP is smaller than that of the SIP at the same height on the leeward side. The data support that the fences have significant sand-control effects, whereas the OIP is better than the SIP.

\subsubsection{Sand-retaining rate}

The sand-retaining rate is the most important index for evaluating the protective effect of sand-control fences, 


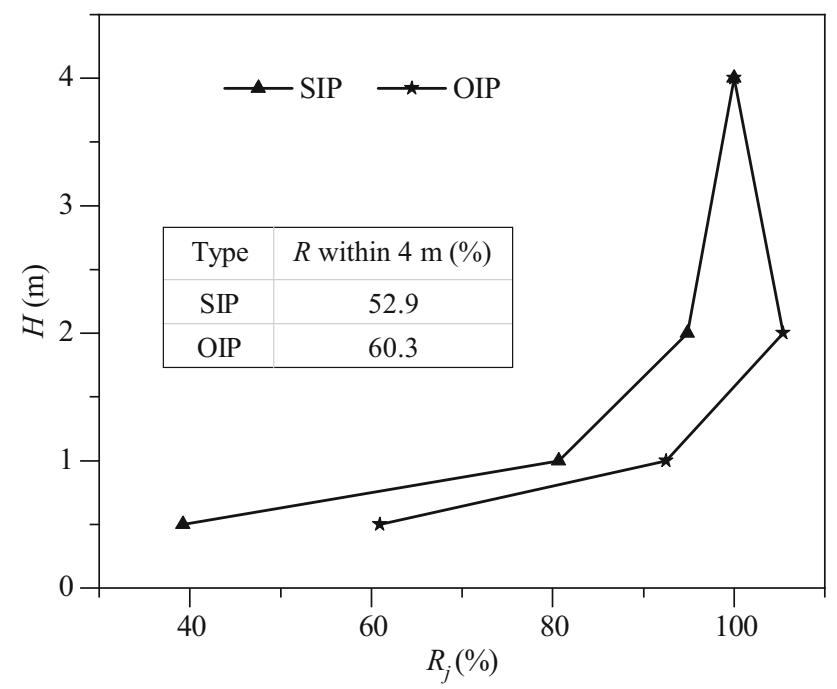

Fig. 14 Cumulative sand-retaining rate and total sand-retaining rate of the fences based on field monitoring during two years of completion of fence installation

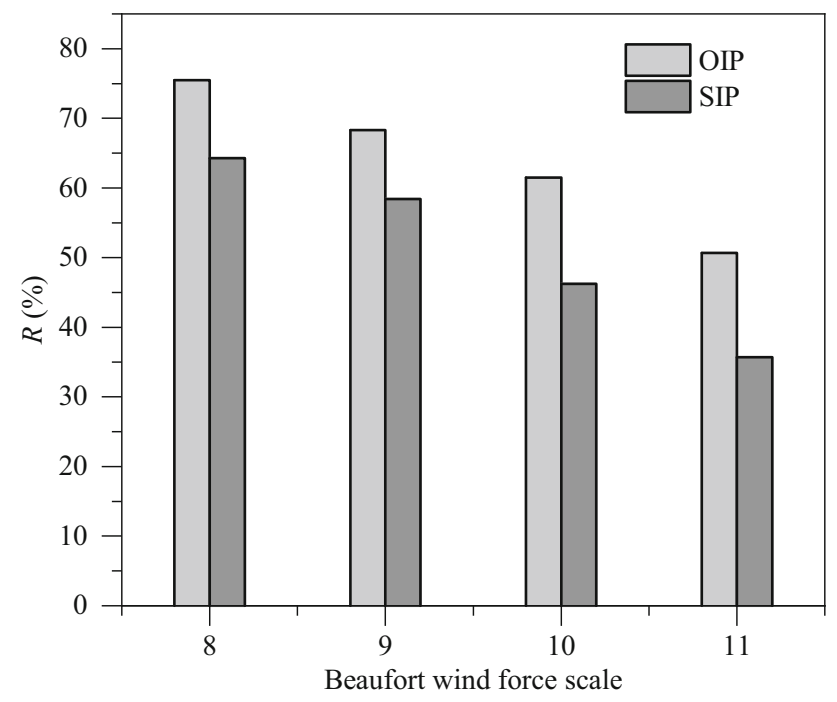

Fig. 15 Relationship between the total sand-retaining rate and the Beaufort wind force levels based on field monitoring

which can directly evaluate the performance of the fences. The sand-retaining rate can be calculated using equations below [7, 28]:

$R_{j}=\sum_{i=1}^{j}\left(q_{\mathrm{w} z i}-q_{\mathrm{l} z i}\right) / \sum_{i=1}^{n}\left(q_{\mathrm{w} z i}-q_{1 z i}\right)$,

$R=\sum_{i=1}^{n}\left(q_{\mathrm{w} z i}-q_{1 z i}\right) / \sum_{i=1}^{n} q_{\mathrm{w} z i}$

where $R_{j}$ is the cumulative sand-retaining rate that is less than or equal to the $j$ th height (\%); $R$ is the total sandretaining rate (\%); $q_{\mathrm{w} z i}$ and $q_{\mathrm{l} z i}$ represent the mass of sand collected at the $i$ th height on the windward and leeward side of the fence $(\mathrm{g})$, respectively.

Figure 11 shows the vertical distribution of the cumulative sand-retaining rate under different wind speeds. The cumulative sand-retaining rate presents an approximate logarithmic distribution with increasing height for three wind speeds used in the wind tunnel tests. Moreover, the sand-retaining rate increases very fast with an increase in the height, which reaches more than $90 \%$ when the height is approximately $0.6 \mathrm{H}$ above the ground surface. More detailed comparisons of the cumulative sand-retaining rates indicate that (1) the two curves almost coincide when the height is below $6 \mathrm{~cm}(0.3 H)$, (2) the two curves gradually become separate when the height is higher than $6 \mathrm{~cm}$ $(0.3 H)$, and (3) the separation degree first increases and then decreases with the height increasing in the range of $0.3 \mathrm{H}$ to $1.0 \mathrm{H}$ and reaches the maximum at $0.75 H$. This implies that the sand-control effect of the two fences does not make a difference when the height is below $0.3 H$, but the OIP fence gradually becomes more effective than the SIP fence as the height increases from $0.3 H$ to $0.75 H$. Note that the cumulative sand-retaining rate of the OIP fence slightly exceeds $100 \%$ at $0.75 \mathrm{H}$ and $0.85 \mathrm{H}$ on the curve, which seems unreasonable. However, it objectively reflects the phenomenon of airflow acceleration at the top of the fence caused by the Venturi effect, which induces a negative sand-retaining of the OIP fence in these areas as the OIP fence has a stronger airflow acceleration effect than the SIP fence. It is noteworthy that the negative sand-retaining rate accounts for less than $3 \%$ of the total sandretaining rate, so the impact on the sand-control efficiency of the fence from the acceleration effect near the top of the OIP fence is insignificant.

Figure 12 shows the sand-retaining rate under different wind speeds. It is also found the total sand-retaining rate of the fences presents a decreasing trend with an increase in wind speed, and the total sand-retaining rate of the OIP is obviously greater than that of the SIP under the same wind speed, which indicates that the higher the wind speed, the worse the effect of the sand-control, and that the sandcontrol effect of the OIP is better than that of the SIP.

\subsection{Field monitoring data}

\subsubsection{Wind speed reduction capacity}

Although the wind directions vary in the field, the wind direction is set perpendicular to the fence model in the wind tunnel test. To be able to more accurately compare the wind speed reduction capacity between the fence model and the actual fence, a period of wind speed time history in the field, whose wind direction is approximately perpendicular to the actual fence, is selected for comparison with 


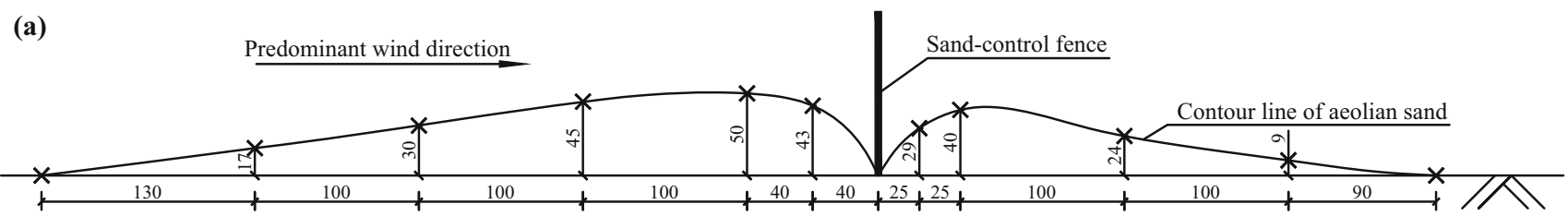

(b)

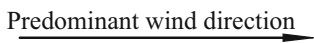

Sand-control fence

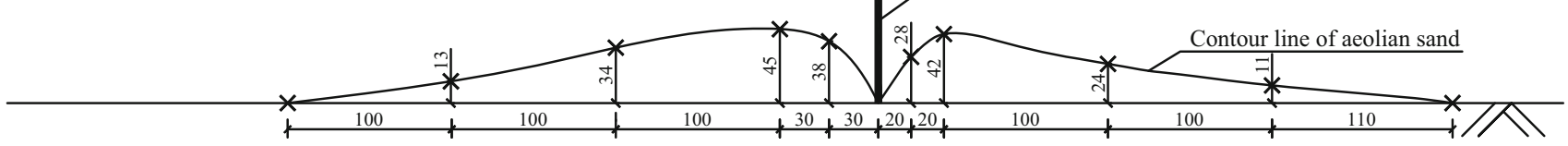

Fig. 16 Contour line of aeolian sand around fences with four years of observations after completion (unit: $\mathrm{cm}$ ): $\mathbf{a}$ OIP and b SIP

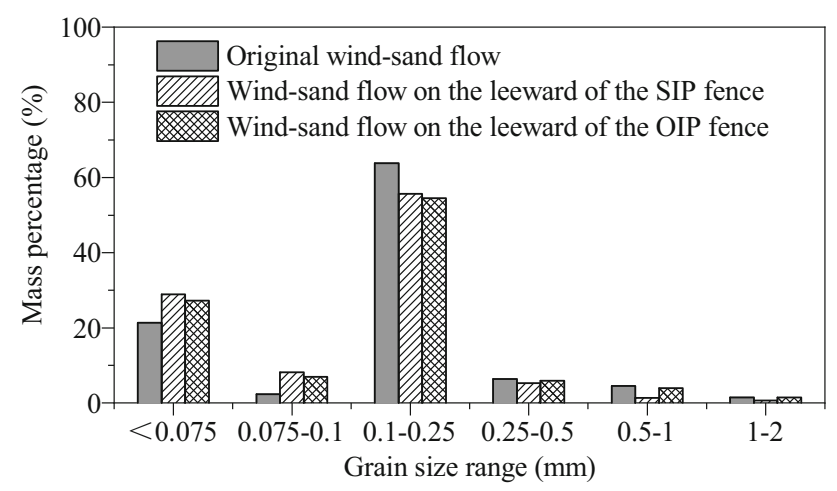

Fig. 17 Grain size distribution in the wind-sand flow within a $4 \mathrm{~m}$ height based on field monitoring

the results of the tunnel test. Figure 13 shows the comparison of the relative wind speed at the height of $0.6 \mathrm{H}$ between wind tunnel tests and field monitoring under the inlet wind speed of about $10 \mathrm{~m} / \mathrm{s}$. Note that the relative wind speed shown in Fig. 13 is normalized to the wind speed at $-10 \mathrm{H}$ instead of the inlet wind speed using Eq. (2). It is observed that their variation trends that are related to the distance from the fence are consistent. It is also found that for the same fence, the wind speed reduction capacity with no aeolian sand around the fence is stronger than that with the accumulated aeolian sand with dimensions shown in Fig. 16. The observation indicates that the gradually increased volume of accumulated aeolian sand over time around the fence can reduce the protection efficiency of the fence. Hence, it is ideal to periodically maintain the fences to ensure they function as designed. Moreover, the comparison results show that the wind speed reduction capability of the SIP fences is significantly weaker than that of OIP fences.

\subsubsection{Sand-control performance}

As shown in Fig. 14, the cumulative sand-retaining rate of the fence during two years of completion of fence installation shows an approximate logarithmic distribution with the height and reaches about $95 \%$ at $2 \mathrm{~m}$. The observation indicates that the effective sand-control range of the fence is below its top. Similar to the results of the wind tunnel test, the cumulative sand-retaining rate of the actual OIP fence at $2 \mathrm{~m}$ is also slightly more than $100 \%$ due to the airflow acceleration effect near the top of the fence. Moreover, the total sand-retaining rate and cumulative sand-retaining rate of the OIP fence at the same height that is within the fence height is significantly higher than those of the SIP fence, which implies that the sand-control efficiency of the OIP fence is significantly better than the SIP fence.

Figure 15 shows the total sand-retaining rate of the fence under different Beaufort wind force levels. Similar to the wind tunnel test results, the total sand-retaining rate of the fences decreases with increasing wind force levels in the field. The main reason is that more sand grains are crossed over the fence with the higher wind speed and the stronger sand-carrying capacity of the airflow, while the sand-retaining efficiency of the fence decreases accordingly. Moreover, the sand-retaining efficiency of the SIP fence is lower than that of the OIP fence for the same wind force level which is in line with the wind tunnel test results.

Figure 16 shows the geometry dimensions of the cumulative aeolian sand around the two types of fences based on four years of observations after the completion of construction [7]. No significant difference in the length and maximum thickness of aeolian sand is found on the leeward between the fences, but it does on the windward side of the predominant wind direction: (1) the total lengths of aeolian sand of the OIP and SIP fence are approximately 510 and $360 \mathrm{~cm}$, respectively, which leads to a difference 


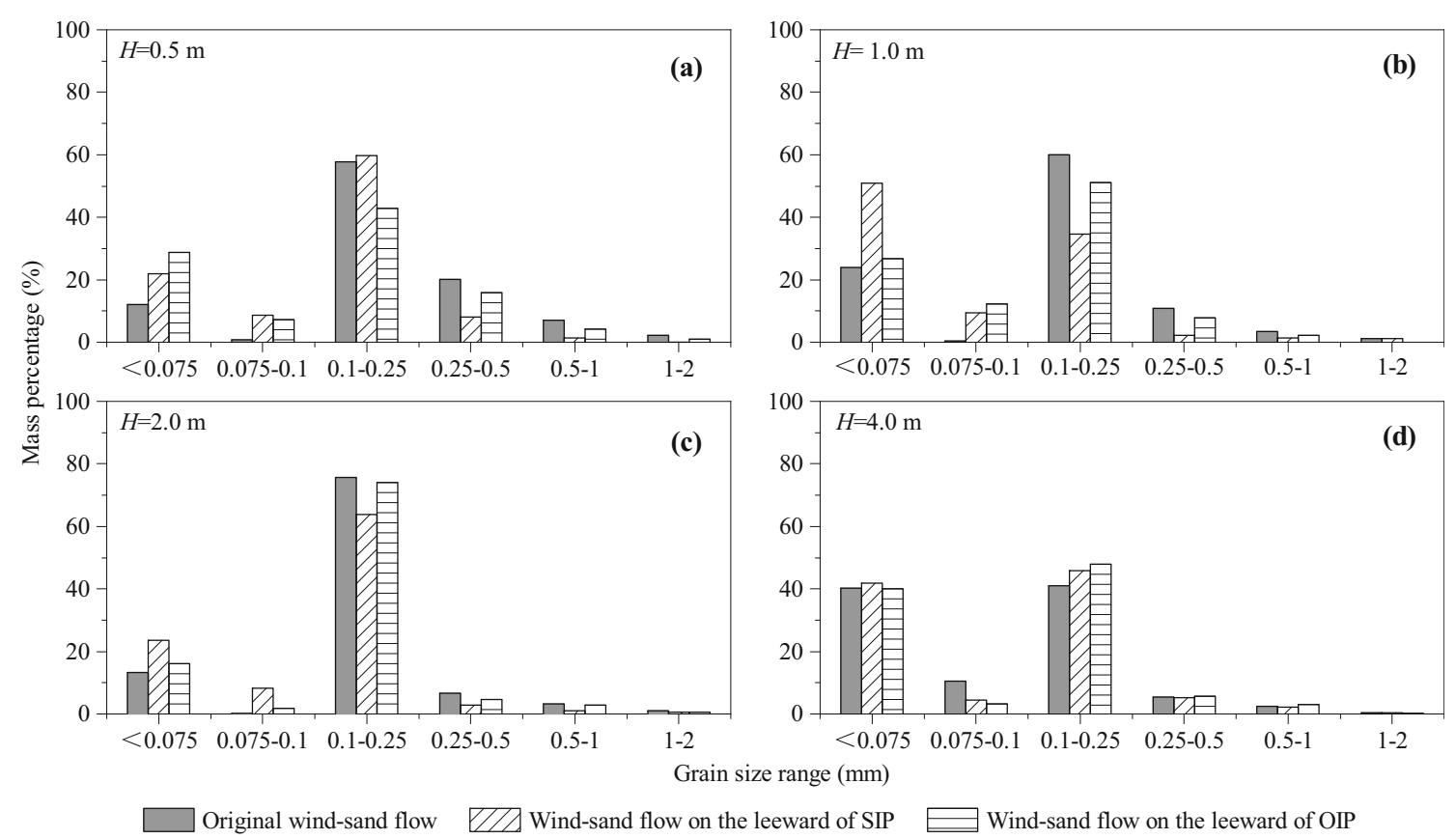

Fig. 18 Grain size distributions of the wind-sand flow at different heights based on field monitoring: a $H=0.5 \mathrm{~m}, \mathbf{b} H=1.0 \mathrm{~m}, \mathbf{c} H=2.0 \mathrm{~m}$, and $\mathbf{d} H=4.0 \mathrm{~m}$

of $150 \mathrm{~cm}$; (2) the maximum thicknesses of aeolian sand are 50 and $45 \mathrm{~cm}$, respectively, with a difference of $5 \mathrm{~cm}$. The total aeolian sand volume per unit length around the SIP and OIP fences is about 1.55 and $1.96 \mathrm{~m}^{3} / \mathrm{m}$, respectively. The difference of sand volume per unit length between the fences is approximately $21 \%$, which indicates that the sand-retaining efficiency of the OIP fence is significantly higher than that of the SIP fence.

\subsubsection{Grain size distribution}

Grain size distribution in the wind-sand flow has the characteristics of stratification along the vertical direction under the action of gravity; the smaller particles are generally in the upper layer whereas the larger particles usually stay near the ground surface. Fences have the function to purify the wind-sand flow, and the particle composition is changed accordingly. Thus analyzing the grain size distribution in the wind-sand flow on both sides of the fence can help to understand the performance of the fence. Figure 17 shows the grain size distribution of the wind-sand flow on the windward and leeward of the fence collected by the spin-type sand collecting instrument in the Yandong wind area. The wind-sand flow at $50 \mathrm{~m}$ windward from the fence (the original wind-sand flow) was dominated by sand grains with particle sizes in the range of $0.1-0.25 \mathrm{~mm}$, accounting for approximately $65 \%$ of the total mass; followed by sand grains with particle sizes less than $0.075 \mathrm{~mm}$, accounting for approximately $20 \%$; and the proportion of other grain sizes is less than $10 \%$. After the wind-sand flow is purified by the fence, the grain size distribution on the leeward side of the fence changes significantly. The sizes of the sand grains are still in the range of $0.1-0.25 \mathrm{~mm}$, but the corresponding proportion is notably reduced by $10 \%$. Moreover, when the grain sizes are less than $0.1 \mathrm{~mm}$, especially in the range of less than $0.075 \mathrm{~mm}$, the corresponding proportion increases by approximately $10 \%$, and the proportion decreases when the grain sizes are greater than $0.1 \mathrm{~mm}$. We can also see that the mass percentage of wind-sand flow on the leeward of the SIP fence is higher than that of on the leeward of the OIP fence for the fine particles, while the opposite is observed with an increase of particle size. The above observations indicate that both fences intercept well for coarser particle sand poorly for finer ones.

Figure 18 shows the grain size distribution of wind-sand flow on both sides of the fences at different heights. Below the height of the fences (i.e., $2 \mathrm{~m}$ ) used in the LWHR, the grain size distributions of each fence at different heights on the leeward side were similar. However, when the height is above the fence $(2 \mathrm{~m})$, the grain size distributions on the leeward side are significantly different from those below the fence height, and the distributions are more similar to those of the original wind-sand flow, which indicates that this height is a critical parameter for the fence to affect the wind-sand flow. The comparison on the grain size distribution for the two fences shows that there are almost no differences in altering the particle composition of wind- 
sand flow above the top of the fence, whereas the OIP fence is more effective than the SIP fence for the sand trapping of the fine particles below the top of the fence.

\section{Discussion}

Wind tunnel test results are generally in line with the field monitoring data. However, the differences between the wind tunnel test and the field monitoring conditions are observed, e.g., surface conditions, wind conditions, etc., and the differences will inevitably affect the results.

As shown in Fig. 13, the on-site wind speed attenuation capacity of the fence is significantly weaker than that of the wind tunnel test, which implies that the wind tunnel test has a trend to overestimate the wind speed reduction capacity of the fence presumably due to the blocking ratio effect; besides, the low aspect ratio of the fence model, the interactions between the boundary layers developing on the sidewalls of the wind tunnel and the wind flow around the fence are also possible reasons that can lead to overestimating the wind tunnel test results.

As shown in Figs. 11 and 14, the total sand-retaining rate measured in the field is significantly lower than that measured by the wind tunnel test. Like wind speed reduction, the wind tunnel test has overestimated the sandretaining efficiency of the fence. Different factors from the wind tunnel tests, including the higher wind speed in the field, the longer wind period of the field monitoring area, and more wind direction variations in the field, may cause the observed differences separately or jointly. Moreover, the change in the airflow field structure around the fence in the field, which is affected by the accumulation of aeolian sand around the fence, may also be one of the main reasons.

In similar wind-sand environments, the two types of fences have different protective efficiency, which is not only related to their induced aerodynamic performance but also related to the interaction between sand grains and the angles of inserting plates. The sand grains in the wind-sand flow hit the inserted plates and deposit in the windward of the fence and the process influences the sand-deposition efficiency. Since the heads and tails of inserted plates of OIP fences are overlapped in horizontal projection, the sand grains cannot easily pass through the gap between the inserted plates in the inserting direction, and the OIP fence has higher efficiency on the windward side.

The flow field structure and the accumulated aeolian sand around the OIP fence are different from those of Cheng et al. [38]. Since this study has a much longer monitoring period, the amount of accumulated aeolian sand on the windward of the fence is much higher than that of Cheng et al.'s study. We also found that the contour shape of the wind speed on the leeward side of the fence is approximately triangular in this study, but it was approximately rectangular in Cheng et al.'s study. Moreover, the shape of the wind speed profile at $20 \mathrm{H}$ is similar to the undisturbed wind profile in this study, but significant deviation from the undisturbed wind speed profile was observed in Cheng et al.'s study. The possible reasons are that the vertical eddy on the leeward side is dominant in this study, but both vertical and horizontal eddies on the leeward side are dominant in Cheng et al.'s study.

\section{Conclusions}

The performance of straight and obliquely inserted concrete-plate fences for sand control along the LWHR was compared and evaluated using the data from wind tunnel tests and field monitoring. The following conclusions can be drawn:

1. Wind tunnel tests show that the effective protection range of the fence is mainly below the top of the fence, and the attenuation amplitude and range of the wind speed on the wake zone of the leeward are significantly larger than that on the deceleration zone of the windward. Moreover, the protection efficiency of the fences shows a decreasing trend with the increase in the incoming wind speed.

2. Comparison of data based on wind tunnel tests and field monitoring concerning airflow field characteristics and sand-control performance shows that the OIP fences have a better wind speed reduction capability, higher sand-retaining efficiency and induces stronger eddy intensity compared with the SIP fences. The particle distribution in the wind-sand flow on both sides of the fence indicates that the OIP fence has a stronger ability to capture fine particles below the top of the fences.

3. The wind tunnel test and field monitoring results are generally consistent. However, differences were also observed. Comparing with the data based on field monitoring, the wind tunnel test has a trend to overestimate the fence's capability, including wind speed reduction capability and the sand-control efficiency. The reasons for wind tunnel test to overestimate the wind speed reduction could be the blocking ratio of the tunnel test, the interaction between the boundary layers developing on the sidewalls of the wind tunnel and the wind flow around the fence, while the sand-control efficiency may be affected by the differences between the laboratory test and field monitoring in terms of ground conditions and the flow 
fields changed by the cumulated sand and multiple wind directions in the field.

4. The increase in the volume of accumulated aeolian sand induced by the fence can weaken their protection efficiency. The study recommended periodically removing the aeolian sand accumulated around the fence to ensure the designed functions.

Acknowledgements This research was supported by the Science and Technology Development Plan of China Railway Group Limited (Grant No. 2015-kj035-g004-03). The authors are thankful for the support. The authors also express their thanks from hearts to the editor and reviewers for their insightful comments, inspirations, and careful reviews that greatly helped the paper.

Open Access This article is licensed under a Creative Commons Attribution 4.0 International License, which permits use, sharing, adaptation, distribution and reproduction in any medium or format, as long as you give appropriate credit to the original author(s) and the source, provide a link to the Creative Commons licence, and indicate if changes were made. The images or other third party material in this article are included in the article's Creative Commons licence, unless indicated otherwise in a credit line to the material. If material is not included in the article's Creative Commons licence and your intended use is not permitted by statutory regulation or exceeds the permitted use, you will need to obtain permission directly from the copyright holder. To view a copy of this licence, visit http://creativecommons. org/licenses/by/4.0/.

\section{References}

1. Dong Z, Chen G, He X et al (2004) Controlling blown sand along the highway crossing the Taklimakan Desert. J Arid Environ 57(3):329-344

2. Han Z, Wang T, Dong $Z$ et al (2007) Chemical stabilization of mobile dune fields along a highway in the Taklimakan Desert of China. J Arid Environ 68:260-270

3. Zhang K-C, Qu J-J, Liao K-T et al (2010) Damage by windblown sand and its control along Qinghai-Tibet Railway in China. Aeol Res 1:143-146

4. Xie S, Qu J, Lai Y et al (2015) Formation mechanism and suitable controlling pattern of sand hazards at Honglianghe River section of Qinghai-Tibet Railway. Nat Hazards 76(2):855-871

5. Zhang C-L, Zou X-Y, Pan X-H et al (2007) Near-surface airflow field and aerodynamic characteristics of the railway-protection system in the Shapotou region and their significance. J Arid Environ 71(2):169-187

6. Wang T, Qu J, Ling Y et al (2017) Wind tunnel test on the effect of metal net fences on sand flux in a Gobi Desert, China. J Arid Land 9(6):888-899

7. Shi L, Wang D, Li K (2020) Windblown sand characteristics and hazard control measures for the Lanzhou-Wulumuqi high-speed railway. Nat Hazards 104:353-374

8. Cornelis WM, Gabriels D (2005) Optimal windbreak design for wind-erosion control. J Arid Environ 61(2):315-332

9. Li B, Sherman DJ (2015) Aerodynamics and morphodynamics of sand fences: a review. Aeol Res 17:34-38

10. Raine JK, Stevenson DC (1977) Wind protection by model fences in a simulated atmospheric boundary layer. J Wind Eng Ind Aerodyn 2:159-180
11. Perera MDAES (1981) Shelter behind two-dimensional solid and porous fences. J Wind Eng Ind Aerodyn 8(1-2):93-104

12. Lee SJ, Park KC, Park CW (2002) Wind tunnel observations about the shelter effect of porous fences on the sand particle movements. Atmos Environ 36(9):1453-1463

13. Dong Z, Qian G, Luo W et al (2006) Threshold velocity for wind erosion: the effects of porous fences. Environ Geol 51(3):471-475

14. Dong Z, Mu Q, Luo W et al (2008) An analysis of drag force and moment for upright porous wind fences. J Geophys Res 113(D4): $1-8$

15. Caborn JM (1957) Shelterbelts and Microclimate. Bulletin-Forestry Commission (RU)

16. Alhajraf S (2004) Computational fluid dynamic modeling of drifting particles at porous fences. Environ Model Softw 19:163-170

17. Jacobs AFG, Wartena L (1987) Flow and turbulence around thin fences in perpendicular and oblique flow direction. Neth J Agric Sci 35:7-20

18. Wilson JD (2004) Oblique, stratified winds about a shelter fence I: measurements. J Appl Meteorol 43:1149-1167

19. Peña A, Bechmann A, Conti D et al (2016) The fence experiment-full-scale lidar-based shelter observations. Wind Energy Sci 1(2):101-114

20. McClure S, Kim JJ, Lee SJ et al (2017) Shelter effects of porous multi-scale fractal fences. J Wind Eng Ind Aerodyn 163:6-14

21. Wang T, Qu J, Ling Y et al (2018) Shelter effect efficacy of sand fences: a comparison of systems in a wind tunnel. Aeol Res 30:32-40

22. Keylock CJ, Nishimura K, Nemoto M et al (2012) The flow structure in the wake of a fractal fence and the absence of an "inertial regime". Environ Fluid Mech 12(3):227-250

23. Telenta M, Duhovnik J, Kosel F et al (2014) Numerical and experimental study of the flow through a geometrically accurate porous wind barrier model. J Wind Eng Ind Aerodyn 124:99-108

24. Lima IA, Araújo AD, Parteli EJR et al (2017) Optimal array of sand fences. Sci Rep 7(45148):1-8

25. Bruno L, Fransos D, Giudice A (2018) Solid barriers for windblown sand mitigation: aerodynamic behavior and conceptual design guidelines. J Wind Eng Ind Aerodyn 173:32-40

26. Dong Z, Luo W, Qian G et al (2007) A wind tunnel simulation of the mean velocity fields behind upright porous fences. Agric For Meteorol 146(1-2):82-93

27. Zhang N, Kang J-H, Lee S-J (2010) Wind tunnel observation on the effect of a porous wind fence on the shelter of saltating sand particles. Geomorphology 120:24-232

28. Cheng J-J, Xue C-C (2014) The sand-damage-prevention engineering system for the railway in the desert region of the QinghaiTibet plateau. J Wind Eng Ind Aerodyn 125:30-37

29. Zhang S, Ding G-D, Yu M-H et al (2018) Effect of straw checkerboards on wind proofing, sand fixation, and ecological restoration in shifting sandy land. Int J Environ Res Public Health 15(10): 2184

30. Bruno L, Horvata M, Raffaele L (2018) Windblown sand along with railway infrastructures: a review of challenges and mitigation measures. J Wind Eng Ind Aerodyn 177:340-365

31. Hong S-W, Lee I-B, Seo I-H (2015) Modeling and predicting wind velocity patterns for windbreak fence design. J Wind Eng Ind Aerodyn 142:53-64

32. Wu X, Zou X, Zhang C et al (2013) The effect of wind barriers on airflow in a wind tunnel. J Arid Environ 97:73-83

33. White BR (1996) Laboratory simulation of aeolian sand transport and physical modeling of flow around dunes. Ann Arid Zone 35(3):187-213 
34. Cheng JJ, Jiang FQ, Xue CX et al (2015) Characteristics of the disastrous wind-sand environment along railways in the Gobi area of Xinjiang, China. Atmos Environ 102:344-354

35. Lee SJ, Kim HB (1999) Laboratory measurements of velocity and turbulence field behind porous fences. J Wind Eng Ind Aerodyn 80:311-326

36. Ma R, Wang J, Qu J et al (2010) Effectiveness of shelterbelt with a non-uniform density distribution. J Wind Eng Ind Aerodyn 98:767-771
37. Dong Z, Wang H, Liu X et al (2004) The blown sand flux over a sandy surface: a wind-tunnel investigation on the fetch effect. Geomorphology 57:117-127

38. Cheng J-J, Lei J-Q, Li S-Y et al (2016) Disturbance of the inclined inserting-type sand fence to wind-sand flow fields and its sand control characteristics. Aeol Res 21:139-151 